\title{
PELATIHAN PEMBUATAN PERATURAN DESA (PERDES) TENTANG PEMANFAATAN PENGELOLAAN DAN PENGEMBANGAN SARANA AIR MINUM DAN SANITASI DI DESA KIJANG MAKMUR KECAMATAN TAPUNG HILIR KABUPATEN KAMPAR
}

\author{
Wasiah Sufi ${ }^{* 1}$, Dwi Herlinda ${ }^{2}$ \\ Fakultas Ilmu Administrasi, Universitas Lancang Kuning \\ e-mail: wasiah.sufi@unilak.ac.id
}

\begin{abstract}
The problems that Badan Pengelolaan Sarana Air Minum dan Sanitasi (BPSPAMS) has not been able to manage the organization and Administration properly and does not have standard rules in the management and utilization of existing facilities so it is necessary Training of Peraturan Desa (PERDES) on Utilization of Management and Development of facilities Water Supply and Sanitation in Kijang Makmur Village Kampar District. Improving the capabilities of BP-SPAMS will help improve the quality of clean water services to the community. Basically, the existence of BP-SPAMS aims to manage, develop, and provide maximum services related to clean water to the public. Clean water service has not been maximized due to the competence of management in running BP-SPAMS organization so that it takes the organization training and management of BP-SPAMS that have the output of the Product that is Village Regulation (PERDES). The outcome of this training is the Kijang Makmur village has a draft PERDES to be ratified.
\end{abstract}

Keywords - Independence, organizational management, PERDES.

ABSTRAK

Permasalahan yang terjadi pada Badan Pengelolaan Sarana Air Bersih dan Sanitasi (BPSPAMS) belum mampu mengelola organisasi dan Administrasi dengan baik dan belum memiliki standar aturan yang baku dalam pengelolaan dan pemanfaatan sarana yang ada sehingga diperlukan Pelatihan pembuatan Peraturan Desa (PERDES) tentang Pemanfaatan Pengelolaan dan Pengembangan sarana Air Bersih dan sanitasi di Desa Kijang Makmur Kabupaten Kampar. Peningkatan kemampuan BP-SPAMS akan membantu meningkatkan kualitas layanan air bersih terhadap masyarakat. Pada dasarnya keberadaan BP-SPAMS bertujuan untuk mengelola, mengembangkan, dan memberikan pelayanan maksimal berkaitan air bersih terhadap masyarakat. Pelayanan air bersih belum maksimal karena kujrang cakapnya pengurus dalam menjalankan organisasi BP-SPAMS sehingga dibutuhkan pelatihan organisasi dan manajemen BP-SPAMS yang memiliki luaran Produk yaitu Peraturan Desa (PERDES).

Kata Kunci: Kemandirian, pengelolaan organisasi, Perdes

\section{PENDAHULUAN}

Desa adalah kesatuan masyarakat yang memiliki batas-batas wilayah yang berwenang untuk mengatur dan mengurus kepentingan masyarakat setempat, berdasarkan asal usul dan adat istiadat setempat yang diakui dan dihormati dalam sistem

Pemerintahan Negara Kesatuan Republik Indonesia. Salah satu wujud kewenangan desa untuk mengatur kepentingan masyarakatn melalui pembentukkan produk hukum desa. Salah satu tujuan dari pembentukkan produk hukum desa untuk menertibkan penyelenggaraan pemerintahan desa serta mengatur pelaksanaan pembangunan dan pelayanan umum. Oleh karena itu, pemahaman 
yang benar terhadap fungsi, kedudukan, dan tata cara pembuatan produk hukum desa menjadi hal penting yang harus diketahui oleh aparat pemerintah desa, agar produk hukum yang dibuat benarbenar dapat berfungsi sebagaimana mestinya dan tidak bertentangan dengan peraturan perundangan yang berlaku.

Berdasarkan Undang-undang Nomor 32 Tahun 2014 tentang Pemerintahan Daerah dengan melaksanakan prinsip desentralisasi dan otonomi daerah, Desa diberi kewenangan untuk mengatur dan mengurus kepentingan masyarakat setempat. Berdasarkan asal usul dan adat istiadat setempat yang dimiliki. dalam rangka pengaturan kepentingan masyarakat, Salah satu implementasi dari kewenangan tersebut adalah desa berkewajiban untuk membuat peraturan desa yang mengatur tata kelola pemerintahan.

Program Pamsimas adalah salah satu program andalan Pemerintah dalam penyediaan air bersih dan sanitasi bagi masyarakat perdesaan melalui pendekatan berbasis masyarakat.

Program ini bertujuan untuk meningkatkan jumlah warga masyarakat berpenghasilan rendah untuk dapat mengakses pelayanan air minum dan sanitasi, meningkatkan penerapan nilai dan perilaku hidup bersih dan sehat dalam rangka pencapaian target akses air minum dan sanitasi pada tahun 2019 di sektor air minum dan sanitasi. Sesuai dengan amanat RPJPN 2005-2025 dan RPJM 2015-2019, Pemerintah melalui program pembangunan nasional 'Akses Universal Air Minum dan Sanitasi Tahun 2019', menetapkan bahwa pada tahun 2019, Indonesia dapat menyediakan layanan air minum dan sanitasi yang layak bagi 100\% rakyat Indonesia. Program pemerintah ini dituangkan dalam bentuk pelaksanaan program PAMSIMAS.

Program PAMSIMAS merupakan Program Nasional Penyediaan Air Bersih dan Sanitasi Berbasis Masyarakat (PAMSIMAS) dengan pola pembangunan pemberdayaan masyarakat yaitu:

1. Memenuhi kebutuhan dasarnya sehingga mereka memiliki kebebasan (freedom), dalam arti bukan saja bebas dalam mengemukakan pendapat,melainkan bebas $d$ ari kelaparan, bebas dari kebodohan, bebas dari kesakitan;

2. Menjangkau sumber-sumber produktif yang memungkinkan mereka dapat meningkatkan pendapatannya dan memperoleh barang-barang dan jasa-jasa yang mereka perlukan;

3. Berpartisipasi dalam proses pembangunan dan keputusan keputusan yang mempengaruhi mereka (Suharto 2005)

Atas dasar PP No. 122 Tahun 2015 tentang sistem penyediaan air minum, yang membahas tentang pengembangna dan pengelolaan sarana air minum baik itu yang dikelola ooeh masyarakat langsung ataupun dikelola oleh BUMN, BUMD dan organisasi lainnya. Tujuan pengelolaan Sarana Penyediaan Air Minum (SPAM) ini adalah untuk memenuhi kebutuhan air minum masyarakat. Dalam hal ini lebih focus pada pengelolaan SPAM dari hasil pembangunan Program PAMSIMAS.

Perguruan tinggi dipandang perlu dalam melakukan pengabdian kepada masyarakat sebagai betuk penguatan Tridarma perguruan tinggi. Dalam kontek konsolidasi kebijakan kepada masyarakat, perguruan tinggi dapat berperan untuk mewujudkan keteraturan dalam pemanfaatan pengelolaan dan pengembangan Air Bersih dan sanitasi yang telah ada dimasyarakat sehingga perlu melakukan bimbingan dan pelatihan sejalan dengan tujuan Program nasional PAMSIMAS.

Wrihatnolo dan Riant Nugroho (2007) menyatakan pemberdayaan berasal dari bahasa inggris "Empowerment" yang juga dapat bermakna " pemberian kekuasaan" karena "power" bukan sekedar "daya", tidak hanya "mampu" tapi juga "menguasai". Mengapa pemberdayaan masyarakat? Paling tidak ada 5 argumen dasar tentang pemberdayaan masyarakat:

1. Demokratisasi pembangunan

2. Penguatan peran organisasi kemasyarakatan lokal

3. Penguatan modal sosial

4. Penguatan kapasitas birokrasi lokal

5. Mempercepat penanggulangan kemiskinan

Demi kenyamanan dan ketertiban dalam pengelolaan SPAM dibutuhkan Badan pengelola yang tangguh, cakap, dan mampu mengembangkan SPAM yang telah ada. Dengan memberikan Pelatihan pengelolaan administrasi BPSPAMS Perdes merupakan salah satu bentuk kontribusi nyata menjalankan tridarma perguruan tinggi dalam bidang pengabdian yang menghasilkan keteraturan 
DINAMISIA - Jurnal Pengabdian Kepada Masyarakat Vol. 1, No. 1 Desember 2017, Hal. 138-144

administrasi dan mampu meningkatkan kualitas pelayanan kepada masyarakat Desa Sungai Tonang Kecamatan Kampar Utara.

Sebagai salah satu Perguruan tinggi yang ada di Privinsi Riau, Universitas Lancang Kuning (UNILAK) menyadari akan pentingnya Kontribusi perguruan tinggi dalam mewujudkan Program pembangunan menuju "Universal Acces" yaitu layanan air minum dan sanitasi yang layak bagi $100 \%$ rakyat Indonesia.

Sejak tahun 2008 program PAMSIMAS dilaksanakan di seluruh Indonesia. Kabupaten Kampar merupakan salah satu kabupaten di Riau yang ikut serta dalam Program Pamsimas.

Tabel 1.1 Data Desa Pamsimas Kabupaten Kampar Tahun 2008- 2014

\begin{tabular}{|c|c|c|c|c|c|c|c|c|c|c|c|c|c|c|c|c|}
\hline \multirow[b]{2}{*}{ NO } & \multirow[b]{2}{*}{ TAHUN } & \multirow[b]{2}{*}{ TOTALDESA } & \multicolumn{3}{|c|}{ KEBERFUNGSIAN } & \multicolumn{4}{|c|}{ PEMANFAATAN } & \multicolumn{3}{|c|}{ IURAN } & \multicolumn{2}{|c|}{ ADM KEU } & \multirow[b]{2}{*}{ PERDES } & \multirow[b]{2}{*}{ REWARD } \\
\hline & & & BERFUNGSI & $\begin{array}{l}\text { BERFUNGSI } \\
\text { SEBAGIAN }\end{array}$ & $\begin{array}{c}\text { TIDAK } \\
\text { BERFUNGSI }\end{array}$ & $\begin{array}{c}\text { SR } \\
\text { (DESA) }\end{array}$ & SR (KK) & $\begin{array}{c}\text { SRt } \\
\text { METERAN }\end{array}$ & NONS & $\angle B O P$ & $>B O P$ & $\begin{array}{l}\text { TANPA } \\
\text { IURAN }\end{array}$ & LENGKAP & $\begin{array}{l}\text { TIDAK } \\
\text { LENGKAP }\end{array}$ & & \\
\hline 1 & 2008 & 9 & 0 & 8 & 1 & 1 & 24 & 1 & 9 & 6 & 1 & 2 & 0 & 9 & 0 & 0 \\
\hline 2 & 2009 & 15 & 0 & 11 & 4 & 0 & 0 & 0 & 15 & 5 & 3 & 7 & 0 & 15 & 0 & 0 \\
\hline 3 & 2010 & 19 & 0 & 11 & 8 & 1 & 107 & 1 & 19 & 15 & 1 & 3 & 1 & 18 & 0 & 0 \\
\hline 4 & 2011 & 27 & 2 & 11 & 14 & 13 & 954 & 11 & 27 & 13 & 7 & 1 & 25 & 2 & 0 & 2 \\
\hline 5 & 2012 & 20 & 2 & 11 & 7 & 6 & 40 & 6 & 20 & 7 & 5 & 8 & 20 & 0 & 0 & 0 \\
\hline 6 & 2013 & 36 & 0 & 3 & 33 & 8 & 199 & 5 & 36 & 17 & 13 & 6 & 2 & 34 & 0 & 15 \\
\hline 7 & 2014 & 10 & 0 & 0 & 10 & 1 & 18 & 1 & 10 & 9 & 0 & 1 & 10 & 0 & 0 & 0 \\
\hline TO & DTAL & 136 & 4 & 55 & 77 & 30 & 1342 & 25 & 136 & 72 & 30 & 28 & 58 & 78 & 0 & 17 \\
\hline
\end{tabular}

Sumber data: PU Cipta Karya Provinsi Riau 2016

Keterangan:

SR

SR

SR (desa)

: Sambungan Rumah

SR (KK)

BOP

$<$ BOP

$>$ BOP

:Sambungan rumah dengan menggunakan meteran air

:Jumlah Desa dengan Sambungan rumah

:Jumlah Kepala Keluarga dengan Sambungan Rumah

: Biaya Operasional

: Iuran lebih rendah dari BOP

: Iuran lebih Besar dari BOP

Desa Kijang Makmur kecamatan Tapung Hilir Kabupaten Kampar merupakan salah satu desa yang mendapatkan bantuan dari program PAMSIMAS pada tahun 2013 berupa pembangunan 1 unit tower air dengan kapasitas $16 \mathrm{~m}^{3}$, jaringan perpipaan sepanjang $1.500 \mathrm{~m}$ dan 3 titik kran umum yang bertujuan untuk memenuhi kebutuhann Air minum dan sanitasi masyarakat. Karena sarana yang telah dibangun dimanfaatkan dengan baik oleh masyarakat maka Desa Kijang Makmur mendapatkan Reward berupa dana HID (Hibah Insentif Desa) pada tahun 2015 dengan membangun 1 Unit Tower air dengan kapasitas $18 \mathrm{~m}^{3}$ serta $500 \mathrm{~m}$ jaringan perpipaan yang bertujuan untuk menambah jumlah masyarakat yang mengakses air bersih.

Dilihat dari komitmen desa maka, pada tahun anggaran 2016 ini Desa Kijang Makmur mendapatkan dana hibah Program Hibah Air minum Pedesaan untuk sebanyak 134 calon Pemanfaat sambungan Rumah. Program hibah air minum pedesaan atau Outputs-Based Approach (OBA) yang bertujuan untuk meningkatkan pelayanan akses air minum dan ditujukan untuk masyarakat yang berpenghasilan rendah. Desa Kijang Makmur telah menerima 3 tahapan program yaitu dana Reguler, dana HID dan Dana OBA. 
DINAMISIA - Jurnal Pengabdian Kepada Masyarakat Vol. 1, No. 1 Desember 2017, Hal. 138-144

Tabel 1.2. Tahapan Pembangunan Program PAMSIMAS di Desa Kijang Makmur Kec. Tapung Hilir

\begin{tabular}{|c|c|c|c|c|c|}
\hline No & Tahun & Pendanaan & Total Dana (Rp) & Kegiatan Fisik dan Non fisik & Keterangan \\
\hline \multirow[t]{6}{*}{1} & 2013 & Reguler APBN & $281,250,000$ & - 1 Unit Tower Air Kapasitas $16 \mathrm{M}^{3}$ & Kegiatan Awal \\
\hline & & & & - 1 unit Sumur Bor dalam & \\
\hline & & & & - 2 unit Kran Umum & \\
\hline & & & & - Jaringan Perpipaan 1.368 m & \\
\hline & & & & - Sarana Sanitasi & \\
\hline & & & & - Kegiatan Pelatihan & \\
\hline \multirow[t]{5}{*}{2} & 2015 & HID & $212,500,000$ & - 1 Unit Tower Air Kapasitas $18 \mathrm{M}^{3}$ & Reward \\
\hline & & & & - 2 unit Kran Umum & \\
\hline & & & & - 1 unit Sumur Bor Dangkal & \\
\hline & & & & - Jaringan Perpipaan 787 m & \\
\hline & & & & - Kegiatan Pelatihan & \\
\hline 3 & 2016 & OBA & & $\begin{array}{l}\text { - jaringan perpipaan dan Meteran } \\
\text { Air untuk Sambungan Rumah }\end{array}$ & Penambaan Pemanfaat \\
\hline \multicolumn{3}{|c|}{ Total } & $493,750,000$ & & \\
\hline
\end{tabular}

Sumber data: Website PAMSIMAS, 2016

Berdasarkan data diatas dari 17 desa yang mendapatkan reward Desa Kijang Makmur merupakan salah satu Desa yang mendapatkan Reward berupa dana HID serta penambahan akses melalui Program OBA. Dari beberapa tahapan pendanaan program yang diberikan pada Desa Kijang Makmur menunjukan investasi pemerintah dan masyarakat dalam membangu rasaran air bersih dan sanitasi telah mencapai Rp. 493.750.000,- (Empat Ratus Sembilan Puluh Tiga Juta Tujuh Ratus Lima Puluh Ribu Rupiah). Sarana air bersih dan sanitasi yang telah dibangun dimanfaatkan oleh masyarakat. Dan biaya operasional sarana bersaral dari iuran masyarakat.

Program Pamsimas merupakan program pembangunan yang berbasis masyarakat dengan pola pemberdayaan masyarakat. Semangat pemberdayaan masyarakat bermuara pada kemandirian masyarakat yang dapat menunjang kehidupan masyarakat secara umum. Dengan total investasi pembangunan sebesar Rp. 493.750.000,- diharapkan Sistem Air Bersih yang telah dibangun mampu berfungsi menjadi PDAM Mini milik masyarakat Desa Kijang Makmur yang bermuara pada pembentukan BUMDes (Badan Usaha Milik Desa) yang bergerak dibidang pelayanan air bersih.

Pada kenyataannya iuran masyarakat hanya mampu menutupi biaya operasional saja. Dari total investasi bangunan yang besar hendaknya dikelola dengan baik sehingga asset yang telah dibangun bisa dimanfaatkan secara maksimal. Hal ini terjadi karena belum ada Peraturan Desa yang dijadikan landasan hukum atas aturan-aturan yang berlaku dalam pengelolaan sarana air bersih. Oleh sebab itu diperlukan aturan yang mengikat untuk pelaksanaan, pemanfaatan, pengelolaan, pengembangan sistem yang dibangun.

Dengan kondisi tersebut, maka diapandang perlu kontribusi perguruan tinggi dalam melakukan pengabdian kepada Masyarakat sebagai bentuk penguatan Tri Dharma Perguruan Tinggi. Sebagai salah satu perguruan tinggi di Riau, Universitas Lancang Kuning (UNILAK) memberikan Pelatihan dalam pembuatan Perdes tentang pemanfaatan pengelolaan dan pengembangan air bersih dan sanitasi kepada masyarakat desa Kijang Makmur Kabupaten Kampar. Hal ini diharapkan dapat menghasilkan produk hukum berupa draf PERDES yang akan disahkan dan di Implementasikan di masyarakat desa Kijang makmur kecamatan Tapung Hilir Kabupaten Kampar.

\section{METODE PELAKSANAAN}

Dalam pelaksanaan pengabdian ini metode yang digunakan yaitu dengan cara ceramah, diskusi dan simulasi pembuatan PERDES. Dalam hal ini ceramah yang dimaksud adalah ceramah yang diberikan oleh pemateri kepada Aparatur Desa di desa Kijang Makmur Kecamatan Tapung Hilir Kabupaten Kampar terkait Pelatihan Pembuatan Peraturan Desa. 
a. Ceramah : melalui Penjelasan Materi, Komunikasi satu arah dari pemateri kepada peserta pelatihan.

b. Diskusi : Diskusi dan menggali informasi antara peserta pelatihan dengan pemateri yang berkaitan dengan materi yang disampaikan.

c. Simulasi: Peserta mempraktekkan cara Pembuatan dan menyusunan dokumen yang berkaitan dengan penyusunan SK, Penyusunan AD/ART, penyusunan PERDES serta kelengkapan administrasi keuangan diarahkan oleh Pemateri.

\section{HASIL DAN PEMBAHASAN}

Desa adalah kesatuan masyarakat yang memiliki batas-batas wilayah yang berwenang untuk mengatur dan mengurus kepentingan masyarakat setempat, berdasarkan asal usul dan adat istiadat setempat yang diakui dan dihormati dalam sistem Pemerintahan Negara Kesatuan Republik Indonesia. Salah satu wujud kewenangan desa untuk mengatur kepentingan masyarakatn melalui pembentukkan produk hukum desa. Salah satu tujuan dari pembentukkan produk hukum desa untuk menertibkan penyelenggaraan pemerintahan desa serta mengatur pelaksanaan pembangunan dan pelayanan umum. Oleh karena itu, pemahaman yang benar terhadap fungsi, kedudukan, dan tata cara pembuatan produk hukum desa menjadi hal penting yang harus diketahui oleh aparat pemerintah desa, agar produk hukum yang dibuat benar-benar dapat berfungsi sebagaimana mestinya dan tidak bertentangan dengan peraturan perundangan yang berlaku.

Sejak tahun 2008 program PAMSIMAS dilaksanakan di seluruh Indonesia. Kabupaten Kampar merupakan salah satu kabupaten di Riau yang ikut serta dalam Program Pamsimas.

Kegiatan pengabdian kepada masyarakat ini dilaksanakan di Desa Kijang Makmur Kecamatan Tapung Hilir Kabupaten Kampar, pada hari Senin tanggal 01 Mei 2017, pada pukul 08.00 Wib dikantor Desa Kijang Makmur. Acara Ini bekerjasama dengan pihak Fasilitator Masyarakat Program PAMSIMAS dan perwakilan dari Tim Ahli di Bidang Hukum yang sekaligus menjadi Narasumber dalam Pelatihan Pembuatan PERDES serta perangkat desa Kijang Makmur yang sangat membantu dan berpartisipasi aktif dalam pelaksanaan Pelatihan ini. Pelatihan pembuatan PERDES ini dihadiri oleh Lurah Kijang Makmur, Sekretaris Lurah, Ketua KKM, Pengurus BPSPAMS, dan perangkat desa lainnya.

Acara pelatihan dibuka oleh sekretaris Desa Kijang Makmur yang dilanjutkan dengan kata sambutan oleh Tim Pengabdian dari Fakultas Ilmu Administrasi Universitas Lancang Kuning. Dalam pelaksanaan pelatihan pembuatan Peraturan Desa (Perdes) Kijang Makmur diawali dengan pemberian Pre Test. Pre Test adalah suatu bentuk pertanyaan, yang dilontarkan kepada peserta pelatihan sebelum memulai kegiatan. Pertanyaan yang ditanyakan adalah materi yang akan disampaikan (materi baru). Pertanyaan itu dilakukan diawal pembukaan kegiatan. Pre test diberikan dengan maksud untuk mengetahui apakah ada diantara peserta pelatihn yang sudah mengetahui mengenai materi yang akan disampaikan.

Adapun manfaat dari diadakan Pre test adalah untuk mengetahui kemampuan awal peserta mengenai materi yang disampaikan. Dari hasil Pre Test ternyata belum semua masyarakat mengerti memahami tata cara penyusunan pembuatan PERDES. Begitu pula dengan aparatur desa, hal ini dibuktikan dengan pertanyaan yang disampaikan terkait dengan aturan-aturan yang berlaku yang harus dimasukan didalam Peraturan Desa.

Tahapan selanjutnya setelah pelaksanaan Pre Test, kegiatan Pelatihan dibagi dalam tiga sesi. Sesi yang pertama yaitu pemaparan materi dari Tim Fakultas Ilmu Adminnistrasi Universitas Lancang Kuning. Dalam sesi ini, materi yang disampaikan terkait bagaimana teknis dalam pembuatan PERDES yang baik dan Sesuai dengan aturan berdasarkan acuan Aturan dan dasar hukum yang berlaku

Sesi kedua disampaikan oleh pihak Tim Fasilitator Masyarakat dari Program PAMSIMAS tentang pentingnya aturan yang baku dalam bentuk Kebijakan Pembuatan Perdes mengenai pengelolaan sarana Air Minum dan sanitasi yang ada di Desa Kijang Makmur. Sesi yang ketiga, disampaikan oleh Tim Ahli dari bidang Hukum, materi yang disampaikan terkait dengan bagaimana proses suatu peraturan sampai dengan di sahkannya peraturan tersebut. Kemudian dilanjutkan dengan simulasi penyusunan pembuatan PERDES yang diawali dengan melihat dasar hukum yang 
diberlaku di Desa Kijang Makmur yang dipandu langsung oleh Tim Fakultas Ilmu Administrasi Universitas Lancang Kuning bersama dengan Tim Fasilitator Masyarakat dan Tim Ahli dibidang Hukum.

Tim melihat respon dari peserta pelatihan sangat baik dan antusias. Hal ini terlihat dari jumlah kehadiran peserta Pelatihan yang cukup banyak dan banyaknya pertanyaan yang di sampaikan oleh peserta pelatihan.

Tahapan terakhir pada kegiatan ini yaitu di berikan Post Tes kepada peserta pelatihan. Post Test merupakan bentuk pertanyaan yang diberikan setelah pelatihan atau setelah materi disampaikan. Singkatnya, post test adalah evaluasi akhir saat materi yang disampaikan pada hari itu dengan tujuan apakah peserta sudah mengerti dan paham memahami mengenai materi yang baru saja diberikan pada saat pelatihan. Manfaat dari diadakan post test ini adalah untuk memperoleh gambaran tentang kemampuan yang dicapai setelah berakhirnya penyampaian pelatihan.

Hasil post test ini dibandingkan dengan hasil pre test yang dilakukan sehingga akan diketahui seberapa jauh efek atau pengaruh dari pelatihan yang telah dilakukan, sekaligus dapat diketahui bagian bagian mana dari bahan penyuluhan yang masih belum dipahami oleh sebagian besar peserta pelatihan.

Dari hasil post test, terdapat peningkatan pemahaman peserta pelatihan dalam penyusunan PERDES, dilihat dari mulai tersusunnya draf acuan aturan-aturan yang akan di gunakan dalam Perdes yang akan di buat, yaitu PERDES tentang pemanfaatan pengelolaan dan pengembangan sarana air minum dan sanitasi di Desa Kijang Makmur kecamatan tapung hilir

Luaran yang diharapkan dengan adanya pelatihan ini adalah bentuk draf PERDES yang disahkan.

\section{KESIMPULAN}

Pada kegiatan pengabdian kepada masyarakat dalam bentuk pelatihan pembuatan PERDES di Desa Kijang Makmur, minat dan motivasi peserta pelatihan sangat antusias. Setelah dilaksanakan pelatihan pada tanggal 01 Mei 2017 tim melakukan monitoring dan evaluasi RKTL yang telah di sepakati bersama.

Dalam monitoring itu Tim banyak menemukan permasalahan yang dihadapi BP-SPAMS dan perangkat desa lainnya dalam menjalankan tugas dan fungsinya. Permasalahan yang dihadapi oleh Bp-SPAMS antara lain; Pertama, Untuk legalitas BP-SPAMS, sudah memiliki SK dari Kades setempat. Namun dalam pembuatan SK masih ada kesalahan yang harus diperbaiki. Sehingga tujuan dan fungsi dari BP-SPAMS tidak berjalan maksimal. Kedua, tidak ada iuran wajib aturan yang mengikat untuk pengguna sarana dikarenakan BP-SPAMS belum paham bagaimana menjalankan organisasi. Ketiga, kurang pendamingan dari Tim Fasilitator Masyarakat kepada BP-SPAMS. Keberhasilan BP-SPAMS tidak terlepas dari kewajiban Tim Pendamping masyarakat dalam menjalankan tugasnya. Keempat, aturan main dalam penggunaan sarana air bersih yang telah dibangun masih belum jelas, sehingga pemanfaat dan pengelolaan sarana air belum maksimal oleh masyarakat. Dengan dilakukan pelatihan pembuatan PERDES tentang pengelolaan pemanfaatan dan pengembangan sarana air minum dan sanitasi di Desa Kijang Makmur ini menjadi produk awal yang dimiliki Desa Kijang Makmur menuju desa yang mandiri.

\section{SARAN}

Dari pelaksanakan kegiatan Pegabdian pada masyarakat ini diharapkan:

1. Kegiatan Pelatihan Pembuatan PERDES ini mampu memiliki draf PERDES yang dapat disahkan dan di implementasikan di desa Kijang Makmur dan dapat dipertanggungjawabkan.

2. Desa harus bisa mandiri dan menjalankan tugas dan fungsinya dengan baik sesuai dengan PERDES yang telah dibuat.

3. Sarana dan prasarana air bersih yang telah ada harus dapat dikelola dikembangkan agar memberikan manfaat besar bagi masyarakat. 
DINAMISIA - Jurnal Pengabdian Kepada Masyarakat Vol. 1, No. 1 Desember 2017, Hal. 138-144

\section{DAFTAR PUSTAKA}

[1] Nogi, Hessel. 2003. "Teori dan Konsep Kebijakan Publik" dalam Kebijakan Publik yang Membumi, Konsep, strategi dan Kasus, Yogyakarta : Lukman Offset dan YPAPI.

[2] Islamy, M. Irfan. 2009. Prinsip-Prinsip Perumusan Kebijakansanaan Negara. Jakarta : Sinar Grafika.

[3] Winarno, Joko. 2007. Teori dan Proses Kebijakan Publik. Yogyakarta: Media Presindo (Anggota IKAPI).

\section{PERATURAN}

1. Undang-undang Republik Indonesia Nomor 25 tahun 2004, tentang Sistem Perencanaan Pembangunan Nasional;

2. Undang-undang Republik Indonesia Nomor 6 tahun 2014, tentang Desa (Lembaran Negara Republik Indonesia Tahun 2014 Nomor 7, Tambahan Lembaran Negara Republik Indonesia Nomor 5494)

3. Undang-undang Republik Indonesia Nomor 23 tahun 2014, Pemerintah Daerah

4. Peraturan Presiden Republik Indonesia Nomor 7 tahun 2005 tentang Rencana Kerja Pemerintah;

5. Peraturan Presiden Republik Indonesia Nomor 78 tahun 2014 tentang Percepatan Pembangunan Desa

6. Peraturan Presiden Republik Indonesia Nomor 165 tahun 2014 tentang Penataa Tugas dan Fungsi Kabinet kerja;

7. Peraturan Presiden Republik Indonesia Nomor 12 tahun 2015 tentang Kementrian Desa, Pembangunan Desa dan Transmigrasi;

8. Peraturan Presiden Republik Indonesia Nomor 47 tahun 2015 tentang Pelaksanaan UU Desa No. 6 tahun 2014;

9. Peraturan Presiden Republik Indonesia Nomor 22 tahun 2015 tentang Dana Desa yang Bersumber dari APBN;

10. Peraturan Menteri Desa Republik Indonesia Nomor 4 tahun 2015 tentang Pendirian, Pengurusan dan Pengelolaan dan Pembubaran Usaha Milik Desa;

11. Permendagri Nomor 111 Tahun 2014 Tentang Pedoman Teknis Peraturan di Desa. 